ISSN: $2594-4827$

\title{
EVASÃO EM CURSOS TÉCNICOS SUBSEQUENTES: EXPRESSÃO DA INCLUSÃO EXCLUDENTE?
}

Inge Renate Frose Suhr ${ }^{1}$

\section{RESUMO}

Este artigo apresenta resultados parciais de uma pesquisa de caráter qualitativo em curso, que investiga os motivos que levam à evasão em cursos técnicos subsequentes. Baseia-se na ideia que a evasão nesses cursos faz parte de um movimento maior, de "inclusão excludente e exclusão includente". Os dados até agora coletados se baseiam em entrevistas realizadas com servidoras que atuam no setor de registro acadêmico (CRA) e no Serviço Integrado de Suporte e Acompanhamento Educacional (SISAE). O grupo de pesquisa tem claro que ainda há muito a investigar para buscar as múltiplas determinações do fenômeno em tela, mas indica preocupação com a naturalização da evasão nos cursos subsequentes, principalmente quando não há ações efetivas no sentido de compreender esse fenômeno para nele atuar.

Palavras-chave: educação profissional e tecnológica, evasão, inclusão excludente

\section{EVASION IN SUBSEQUENT TECHNICAL COURSES: EXPRESSION OF EXCLUDING INCLUSION?}

\begin{abstract}
The reflection presented in this text is based on the idea that school dropout in subsequent technical courses is part of a larger movement, called "excluding inclusion and inclusive exclusion". The article expresses partial results of a research of qualitative character still in course, that aims to investigate the reasons that lead to the evasion, as well as those that favor the permanence of the student in these courses. The data collected are based on interviews with campus servants working in the academic record (CRA) and the Integrated Support and Educational Support Service (SISAE). The research group is clear that there is still a lot to investigate to find the multiple determinations of the phenomena on the screen, but it indicates concern about the naturalization of evasion in subsequent courses, especially when there are no effective actions to understand this phenomenon to act on it.
\end{abstract}

Keywords: professional and technological education, evasion, exclusion

\footnotetext{
${ }^{1}$ Professora no Instituto Federal Catarinense - IFC. E-mail: ingesuhr2011@gmail.com
} 


\section{INTRODUÇÃO}

Nosso país vive índices crescentes de desemprego e a grande mídia vem difundindo maciçamente a ideia que o problema se encontra no baixo nível de qualificação do trabalhador, empurrando para o próprio indivíduo a responsabilidade por uma questão que, na verdade, encontra explicação no funcionamento do capitalismo.

SUHR (2014, p.147) assevera que a produção flexível - mesmo que combinada com estratégias advindas do padrão taylorista-fordista - se organiza em cadeias produtivas e estas combinam

diferentes tipos de trabalho, dos mais simples aos mais sofisticados, e, portanto, traz demandas diferenciadas, e desiguais, de qualificação dos trabalhadores. As empresas combinam trabalhos mais simplificados a outros mais complexos para garantir lucratividade à linha de produção.

É possível indicar, portanto, que o nível de formação não é, do ponto de vista do capital, impeditivo para a inserção no mercado de trabalho, contradizendo o discurso de senso comum que assim justifica o desemprego.

Por outro lado, "há uma cadeia de qualificação profissional, que articula educação geral, formação profissional e experiência (...) e quanto mais se articulam essas dimensões e em níveis mais complexos, maiores as possibilidades de ingresso nas empresas mais dinâmicas da cadeia produtiva". (SUHR, 2014, p.149) Nesse sentido, a oferta de cursos de qualificação profissionais pode ser um elemento potencializador da inserção no trabalho de maneira menos precarizada.

Para o trabalhador que já concluiu a educação básica e não teve oportunidade de continuar os estudos em nível superior, uma possibilidade de qualificação profissional se encontra nos cursos técnicos pós-médios, que, em conformidade com o artigo 36-B da Lei de Diretrizes e Bases da Educação Nacional (Lei 9.394/96), são denominados subsequentes.

Reconhecendo que a conclusão de um curso técnico subsequente pode ser um dos elementos que potencializam, embora apenas de maneira mediata, a inserção no trabalho, e que a evasão pode ser analisada a partir do par categorial "inclusão excludente e exclusão includente" (KUENZER, 2002), esse artigo expressa os resultados, ainda parciais, de uma pesquisa em curso que objetiva investigar os motivos que levam à evasão, assim como aqueles que favorecem a permanência do estudante. 
O lócus da pesquisa é um Instituto Federal de Educação, Ciência e Tecnologia, situado na região sul do Brasil e para fins desse artigo são apresentados dados e conclusões parciais, referentes a apenas um dos campi da referida instituição.

Dados da Plataforma Nilo Peçanha ${ }^{2}$ demonstram que atingir de maneira efetiva o público que frequenta os cursos técnicos subsequentes é um desafio, pois os índices de evasão são elevados. O público desse tipo de curso é formado por pessoas que já atingiram a maioridade e possuem responsabilidades diferentes dos adolescentes que seguem o ciclo normal de formação básica. Comumente são pessoas que se ocupam no trabalho informal ou atuam em funções simples em empresas do entorno da instituição e são responsáveis pelo sustento (mesmo que não sozinhos) da família. Geralmente retornam à escola em busca de profissionalização com base na expectativa de ampliarem as possibilidades de inserção no mercado de trabalho e/ou de ascenderem profissionalmente nas empresas em que atuam. Soma-se a isso que geralmente foram excluídos da possibilidade de continuidade dos estudos em nível superior.

As situações concretas de vida do alunado, além de outros elementos que a presente pesquisa está mapeando, se refletem em um índice alto de evasão, o que resulta em números muito baixos de conclusão dos cursos subsequentes. Infelizmente, em muitos casos o alto índice de evasão é naturalizado, sendo a responsabilidade impingida aos usuários e justificada por elementos extraescolares.

É nesse cenário que se insere a pesquisa, buscando compreender, para além da aparência fenomênica, as razões que favorecem a permanência e a evasão dos estudantes nos cursos subsequentes. Para reunir dados que permitam a análise dessa realidade complexa, as estratégias estão sendo as seguintes: entrevistas com alguns profissionais do campus, a saber: I. coordenadora da Coordenação de Registro Acadêmico; II. pedagoga, assistente social e psicóloga atuantes no Serviço Integrado de Suporte e Acompanhamento Educacional; III. questionários enviados aos docentes que atuam no curso; IV. entrevistas coletivas (grupo focal) com estudantes dos cursos subsequentes; e V. envio de questionário por e-mail aos estudantes evadidos.

No momento em que escrevemos esse texto, ainda não foi possível colher as informações advindas dos professores e estudantes, portanto, as conclusões que aqui

\footnotetext{
2 Para informações sobre os índices de evasão nos cursos técnicos subsequentes, consultar a Plataforma Nilo Peçanha: http://plataformanilopecanha.mec.gov.br/
} 
apresentaremos são parciais, podendo ser revistas com o continuar da pesquisa. Importa citar também que todo objeto de pesquisa precisa ser situado no que já foi produzido pela comunidade acadêmica sobre ele, para o que passaremos a apresentar o referencial teórico que embasa o trabalho.

\section{EDUCAÇÃO PROFISSIONAL E DUALIDADE ESTRUTURAL}

A educação profissional no Brasil teve início como estratégia destinada a tirar das ruas os pobres e desvalidos da sorte, dando-lhes condições mínimas de sustento para que não dependessem do Estado. Com o passar do tempo e o início da industrialização, assumiu também a função de preparar os operários desejados pelo setor produtivo. Tratava-se de uma educação de classe, já que para os filhos das elites o caminho era outro, baseado numa educação propedêutica, com o objetivo de acessarem ao ensino superior e também se tornarem dirigentes.

$\mathrm{Na}$ medida em que se alteram as expectativas do setor produtivo em relação ao tipo de trabalho a ser realizado, a educação profissional foi sendo adequada, mas com o interesse em formar trabalhadores que conhecessem (apenas) os processos de fabricação. Seu objetivo tradicionalmente era pragmático, ofertando formação instrumental e não havia a preocupação em garantir aos trabalhadores a apropriação do saber escolar, compreendida aqui como possibilidade de transformação da sociedade.

Kuenzer (2000, p. 26) considera "a dualidade estrutural a categoria explicativa da constituição do ensino médio e da educação profissional no Brasil”, pois se configura claramente a existência de dois caminhos de formação, um geral e outro profissionalizante, destinados a públicos diferentes a partir de sua origem de classe. A autora esclarece ainda que a dualidade não pode ser resolvida no âmbito escolar, já que sua origem está na desigualdade das classes sob o capitalismo.

Apesar da impossibilidade de vencer a dualidade estrutural, num passado mais recente foram surgindo propostas de formação profissional que pretendem contribuir para a educação integral, compreendida como aquela que tem como horizonte a superação da divisão do ser humano imposta pela divisão social do trabalho "entre a ação de executar e a ação de pensar, dirigir ou planejar.” (CIAVATTA, 2005, p.85). Trata-se de favorecer, mesmo dentro dos limites impostos pela organização capitalista, uma formação que vá além da preparação para o trabalho simples, permitindo aos seus usuários, o "domínio 
dos fundamentos das técnicas diversificadas utilizadas na produção, e não o mero adestramento em técnicas produtivas."(SAVIANI, 2007, p.161).

Em grande medida a educação profissional foi impulsionada com a criação dos Institutos Federais de Educação, Ciência e Tecnologia (IFs), em 2008, que expressa, em nível de política pública, a intenção de ampliar as oportunidades educacionais daqueles que habitam fora dos grandes centros urbanos, nos quais, por muito tempo, se concentraram as matrículas no ensino médio e superior. Essas instituições têm por missão, oferecer educação profissional e tecnológica em todos os níveis, desde a qualificação profissional que não exige escolaridade prévia, até a pós-graduação, embora, segundo a lei que os criou (Lei 11.892/08), 50\% das vagas devam ser destinadas ao ensino médio integrado.

A proposta de educação integral defendida pelos IFs deve orientar as ações em todos os níveis e modalidades ofertados, inclusive os cursos subsequentes, objeto desse estudo. Propor que a formação profissional tenha como meta formar pessoas que não só estejam preparadas para atuar no setor produtivo, mas que o façam com um nível maior de compreensão dos processos (domínio intelectual da técnica) é contribuir, a médio e longo prazo, a transformação da sociedade. Por isso mesmo, favorecer a permanência dos estudantes nos cursos ofertados vai além de meramente corresponder às expectativas do estudante ou do mundo do trabalho. Significa ampliar as possibilidades de transformação social e é nesse sentido que estudos sobre permanência e evasão se justificam e ganham importância. Eles podem servir como instrumentos de gestão das instituições e do sistema em geral, superando as exigências de eficiência e eficácia do sistema baseadas apenas em critérios quantitativos.

\section{EVASÃO ESCOLAR}

Evasão pode ser conceituada como o abandono do ciclo escolar pelo aluno regularmente vinculado a um curso da instituição. Dito de outro modo, é a situação em que o estudante deixa de frequentar as aulas, não conclui o curso no qual estava matriculado. Todos os autores consultados, dentre os quais citamos ANGELUCCI et al,( 2004); FINI; DORE; LÜSCHER (2013), DORE e LÜSCHER (2011), MACHADO (2009), consideram que a evasão não tem explicação única, sendo multifatorial, com especificidades ligadas a cada curso, instituição e região geográfica. 
Vários estudos acima citados relatam a dificuldade em estabelecer qualitativamente os motivos que levam à evasão, principalmente pela dificuldade de compor bases de dados de alunos egressos, sejam eles evadidos ou diplomados. Indicam ainda que, embora as causas da evasão sejam difíceis identificar, ela sempre é influenciada por um conjunto de fatores que se relacionam tanto ao estudante e à sua família quanto à escola e à comunidade em que vive.

De maneira geral, pode-se considerar que há fatores intraescolares e extraescolares que potencializam o risco de evasão. Como fatores extraescolares é possível citar o cansaço ocasionado pelo trabalho, o custo de transporte, a dificuldade em conciliar trabalho e estudo, as pressões familiares, dificuldades financeiras, dentre outros. Como fatores intraescolares, podemos mencionar. inadequação do currículo, a falta de contextualização dos conteúdos, dificuldades nas relações professor-aluno e aluno-aluno, metodologia de ensino inadequada...

Dentre os trabalhos que apontam a relevância dos elementos extraescolares, Johann (2012) conclui que não são apenas os fatores econômicos que motivam a evasão, apontando a importância de considerar as dificuldades para conciliar o trabalho com as exigências dos cursos. A mesma autora aponta, por outro lado, fatores intraescolares, como a influência do alto índice de reprovação em algumas disciplinas para a evasão.

Já Machado (2009) tomando como objeto de estudo a evasão numa escola agrotécnica de nível médio, indica a presença de fatores intraescolares como responsáveis por esse fenômeno, além de apontar a diferença de percepção de professores, técnicos e estudantes em relação a essas causas.

Figueiredo e Sales (2017) trazem como elementos a serem considerados, além dos já citados, as dificuldades pessoais - sejam de aprendizagem, emocionais, ou de outra natureza - a influência de amigos e a falta de ações institucionais e/ou governamentais no sentido de criarem estratégias que favoreçam a permanência do estudante com êxito. As autoras alertam que as características do corpo discente, a qualidade do espaço físico, os recursos escolares, a qualidade da relação professor-aluno são relevantes na permanência e/ou evasão. Ressaltam que, infelizmente, há uma naturalização da evasão, razão pela qual pouco se faz - seja na instituição escolar ou em nível de políticas públicas - para favorecer a permanência do estudante. 
Nesse mesmo sentido, Setúbal (2010, p.357) ressalta que há situações em que se instala na escola "uma violência simbólica, muitas vezes camuflada, perpassando as interações sociais ali construídas por meio de diferentes atitudes e regras invisíveis". Estão incluídas nessa violência a falta de acolhimento, a distância entre o currículo formal e a realidade dos alunos, a desvalorização das vivências dos alunos e suas famílias, a dificuldade em lidar com a diversidade e as posições preconceituosas.

Importa ressaltar que embora vários estudos analisados se refiram aos Institutos Federais, são muito poucos os que focam nos cursos subsequentes. O estudo de Oliveira (2016, p.119) é uma dessas exceções e conclui que embora haja fatores internos à instituição,

motivos extraescolares parecem ser os mais frequentes na percepção dos estudantes. O principal motivo é a incompatibilidade do trabalho com o estudo, pois a maioria não deu conta de manter as duas atividades concomitantemente, priorizando o trabalho para suprir suas urgências de consumo e bem estar.

Mesmo assim, a dificuldade de aprendizagem, a violência simbólica advinda principalmente de um currículo pouco significativo, bem como a não-identificação do aluno com o curso são apontados pela autora como fatores relevantes.

Com base no referencial teórico que orienta nossa reflexão, consideramos que a evasão escolar faz parte do processo denominado por Kuenzer (2002) como "exclusão includente e inclusão excludente" para se referir às relações entre educação e trabalho sob a égide da produção flexível. A exclusão includente se refere ao movimento em processo no mundo do trabalho e se caracteriza por

várias estratégias de exclusão do mercado formal, onde o trabalhador tinha direitos assegurados e melhores condições de trabalho, acompanhadas de estratégias de inclusão no mundo do trabalho através de formas precárias. (KUENZER, 2002, p. 92).

A esta lógica do mercado se equivale, em direção contrária, a inclusão excludente,

ou seja, as estratégias de inclusão nos diversos níveis e modalidades de educação escolar aos quais não correspondam os necessários padrões de qualidade que permitam a formação de identidades autônomas intelectual e eticamente... (KUENZER, 2002, p. 92).

A autora considera que todos os processos escolares precarizados são orgânicos ao funcionamento do capitalismo, pois ajudam a criar um contingente de pessoas pouco 
qualificadas, que precisarão se submeter a trabalhos simples e em piores condições, tendendo a incorporar o fracasso como sendo delas e não do sistema.

Como os cursos subsequentes são destinados a quem já concluiu o ensino médio e não pôde continuar os estudos, é possível aventar a hipótese que a evasão nesse tipo de curso pode contribuir para que o estudante se sinta, mais uma vez, responsável por sua própria exclusão. Dito de outro modo, do ponto de vista do ingresso, foi-lhe dado o acesso à formação profissional - que poderia contribuir para sua inserção no trabalho em postos menos precarizados. Mas, se ele não consegue concluir o curso, há uma tendência do estudante/trabalhador a assumir para si - por meio de justificativas como problemas pessoais, incompatibilidade de horários com o trabalho - a responsabilidade pela sua exclusão.

\section{METODOLOGIA}

A pesquisa em curso segue a abordagem qualitativa, embora objetive estabelecer parâmetros quantitativos no que se refere às razões que levam à evasão ou à permanência do estudante nos cursos técnicos subsequentes. Busca compreender, para além do dado quantitativo, as particularidades e vivências dos sujeitos de pesquisa sobre a evasão em cursos técnicos subsequentes.

Apoia-se na compreensão que todo objeto de pesquisa é uma faceta do real, faz parte de uma totalidade. Por isso, não basta compreender a faceta, é preciso relacioná-la com a síntese das múltiplas relações que originaram o fenômeno em questão.

Dado que a realidade não se mostra como é, que há muitas mediações que precisam ser compreendidas, são necessárias sucessivas aproximações para superar a imediaticidade do fenômeno (aparência) e alcançar a totalidade. É nesse sentido que os dados quantitativos serão cotejados com a percepção de estudantes, professores e profissionais atuantes nos setores de apoio (SISAE).

A primeira etapa de pesquisa consistiu na busca de referencial teórico sobre evasão na Biblioteca Digital Nacional de Teses e Dissertações (BDTD), no site SCIELO e no site da Associação Nacional de Pesquisa e Pós-graduação em Educação (Anped). Após aprovação do no Comitê de Ética em Pesquisa com Seres Humanos, iniciaram-se os procedimentos de coleta de dados a campo, que continua sendo realizada. Até o momento em que esse texto é trazido a público já foram realizadas as entrevistas com 
ISSN: $2594-4827$

coordenadora da Coordenação de Registro Acadêmico (CRA) e com as profissionais atuantes no Serviço Integrado de Suporte e Acompanhamento Educacional (SISAE). Está em processo a coleta de respostas aos questionários enviados aos docentes.

\section{OS RESULTADOS}

Os dados parciais até agora coletados indicam a multiplicidade de pontos de vista acerca do tema. Do ponto de vista da coordenadora de Registro Acadêmico, a responsabilidade recai sobre o aluno. Tal conclusão da servidora se apoia em dois elementos: a) são poucos os que comparecem ao setor para efetivar o trancamento ou comunicar a desistência: simplesmente deixam de vir às aulas; b) o preenchimento das fichas por parte dos que comparecem à CRA para efetivar o desligamento. Nessas fichas o aluno é convidado a descrever o(s) motivo(s) que levam ao desligamento e, segundo a servidora, a totalidade das respostas se referem a dificuldades em conciliar estudo e trabalho e questões pessoais.

Quando questionada se haveria possiblidade de haver outras motivações para o desligamento e essas justificativas se referirem apenas a elementos que os alunos considerariam aceitáveis pela instituição, a coordenadora considera que essa hipótese é válida. Ainda nessa direção perguntamos se no momento em que comparecem à CRA para efetuar o desligamento, os estudantes deixam transparecer outras possíveis motivações. A servidora aventa a possibilidade de haver outras razões, comentando que muitas vezes o estudante se sente constrangido na hora de solicitar o desligamento, como se ele tivesse fracasso. Ela considera que "jogar a responsabilidade em problemas pessoais, financeiros ou de trabalho tira a responsabilidade da pessoa, como se não fosse ela que fracassou, que não conseguiu continuar". A servidora comenta ainda que já se construiu na instituição a visão que a evasão alta nos cursos subsequentes é algo comum.

Quando perguntamos se ela observa alguma causa interna para a evasão, ela cita que talvez os alunos não sejam bem informados, antes do ingresso, sobre como funciona e quais são as exigências do curso. Segundo ela, os alunos adultos "não têm paciência para estudar teoria, eles chegam aqui achando que vão aprender a fazer, e o curso é teórico, tem muita coisa pra estudar."

Finalmente, ainda segundo a coordenadora da CRA, a forma como se dá o ingresso nos cursos subsequentes está equivocado e pode ser elemento de evasão. O 
ingresso, quando há mais candidatos que vagas, se dá por meio de sorteio público. A instituição entende que esta é uma forma mais democrática, evitando realizar uma seleção por meio de teste. E é exatamente a falta de um teste de seleção que a servidora aponta como problemática. Segundo ela,

o sorteio é uma entrada fácil num curso que exige uma base, exige dedicação, estudo... como a inscrição é gratuita e não há teste de seleção, os candidatos acreditam que será um curso fácil, ou ainda, se inscrevem sem a mínima noção do que é o curso. Quando a entrada é fácil, a saída também é. Aqui na nossa região tem muito curso a distância, as pessoas acostumaram a não ter que estudar muito. Daí chegam aqui e é puxado, além de ter aula toda noite, eles repensam. Fazer a distância é mais fácil e cada vez mais barato.

As próximas entrevistas foram com três profissionais do Serviço Integrado de Suporte e Acompanhamento Educacional (SISAE): pedagoga, assistente social e psicóloga. Evidenciou-se nessas entrevistas que embora esse setor esteja à disposição de toda a comunidade escolar, é pouco requisitado pelo estudante do subsequente. Os programas oficiais de assistência estudantil ${ }^{3}$ são pouco acessados por estudantes desse curso, de modo que em 2019 não há nenhum aluno recendo auxílio. Segundo a assistente social, embora ela tenha apresentado o programa, não houve procura por parte desse público. Quando questionada se há algum outro tipo de atuação da assistência social com os alunos do subsequente, afirma que não, mas ressalta que, se for acionada, estará à disposição desses alunos.

A pedagoga entrevistada relata que o setor está com menos servidores que o necessário, o que implica em estabelecer prioridades de ação e que, a partir da lei que criou os IFs e por decisão dos servidores do setor, o atendimento mais direto é com os alunos e professores do ensino médio integrado. Ela assume que os cursos subsequentes e superiores, que ocorrem à noite, recebem menos atenção e afirma se sentir incomodada com essa situação, mas sem condições concretas de mudar a realidade em curto prazo.

Em relação à evasão, afirma não ter certeza dos fatores intervenientes, mas levanta a hipótese de haver aspectos internos à instituição que estariam contribuindo significativamente. Segundo a pedagoga, as questões pedagógicas - organização do

\footnotetext{
${ }^{3}$ PAE - Programa de Auxílios Estudantis: tem por objetivo criar condições de acesso e aproveitamento pleno da formação acadêmica aos estudantes em situação de vulnerabilidade socioeconômica, por meio da concessão de auxílios estudantis.
} 
planejamento, metodologia, avaliação, organização de atividades específicas de cada curso - ficam a cargo do coordenador e do colegiado do curso. Como a maioria dos docentes do curso em questão é bacharel e o curso é de uma área que exige alto nível de abstração, pode ser, segundo ela, que os docentes não saibam trabalhar os conteúdos de maneira acessível e significativa. Diz ela:

Os professores viveram como alunos, uma escola excludente. Isso ainda é muito forte! Eles acham que só devem ir adiante os que eles chamam de bons, que os que têm dificuldade devem ser excluídos, para manter a qualidade do curso. Não posso afirmar que todos sejam assim, mas noto que para muitos professores é normal que poucos sejam aprovados.

Essas considerações trazem à tona uma questão preocupante: se os professores ainda têm uma visão excludente de escola, evasão pode ser considerara por eles como manutenção da qualidade do curso. Perguntamos à mesma servidora se há ações que busquem minimizar dificuldades acadêmicas dos alunos. Ela citou que os professores têm horários de atendimento, mas que os alunos não procuram. Relatou ainda que podem ser organizados aulões, cursos de nivelamento, mas que não se recorda de nenhum que tenha ocorrido para os cursos subsequentes.

A psicóloga do setor diz que são raros os estudantes de cursos subsequentes que a procuram, pois eles estabelecem pouco vínculo com a instituição. Para ela, tais “estudantes não se sentem parte da escola, eles vêm apenas para assistir às aulas, não participam de nenhuma outra atividade. Eles conversam entre si, convivem entre si, trocam ideias sobre o trabalho, futebol, pouco se envolvem." Perguntada se a falta de vínculo pode ser um fator de evasão, a servidora considera que sim e ressalta que o contrário também é válido, já que um ambiente árido e pouco receptivo pode ser fator de evasão. Lembra ainda que é preciso muita motivação e força de vontade para estar em sala de aula todas as noites depois de uma jornada de trabalho extenuante, que no caso desse curso é prioritariamente na linha de produção em indústrias da região. A psicóloga considera que uma atitude humana por parte dos professores, compreendendo as dificuldades dos alunos poderia ser uma forma de favorecer a permanência e o sucesso na aprendizagem. 


\section{CONSIDERAÇÕES PARA A CONTINUIDADE}

Demos a essa seção o título de considerações para continuidade porque os dados até coletados não permitem conclusões relativas ao objetivo que nos propusemos: investigar os motivos que levam à evasão, assim como aqueles que favorecem a permanência, do estudante em cursos subsequentes.

Buscando manter coerência com o referencial teórico adotado, e compreendendo que todo objeto precisa ser compreendido para além da aparência inicial, temos claro que muito ainda é preciso fazer para buscar as múltiplas determinações do fenômeno em tela.

De todo modo, embora os dados até aqui coletados não se diferenciam muito do que já vem sendo apontado pelas pesquisas sobre evasão, consideramos relevante indicar elementos para orientar continuidade de nossa pesquisa.

Inicialmente assinalamos que apesar da multiplicidade de pontos de vista de nossas entrevistadas, suas falas se complementam e não apresentam contradições e, ao que indicam os dados até aqui colhidos, poderia haver ações da instituição no sentido de minimizar o índice de evasão.

Quando a coordenadora da CRA se refere ao constrangimento do estudante na hora de solicitar o desligamento, relacionando esse momento como se o aluno precisasse assumir seu próprio fracasso, nos alerta para a concepção de escola ainda presente em nosso país, que empurra para o usuário o ônus de seu insucesso. Ao fazê-lo, pode favorecer a inclusão excludente, categoria criada por Kuenzer (2005) para explicar as situações em que a escola recebe, formalmente, um público antes excluído, mas o exclui novamente por uma série de fatores e, acaba por culpabilizar o próprio estudante pela exclusão. Jogar a responsabilidade do fracasso - unicamente - para o estudante contribui idelogicamente para que ele se sinta incapaz e, por isso mesmo, tenda a aceitar o status quo sem questionamento e a aceitar postos de trabalho mais precários.

Também a concepção de educação como espaço em que só os melhores devem se formar e que, segundo a pedagoga perpassa a naturalização da evasão, é um aspecto muito preocupante. As ações citadas como possiblidades de enfrentamento das dificuldades acadêmicas dos alunos, tais como aulões e atendimentos individualizados não ocorrem à noite e, portanto, terão pouca efetividade junto ao público trabalhador.

Aspectos citados, como a importância do vínculo com a instituição, atitudes dos docentes no sentido de compreender a realidade do estudante trabalhador e, a partir disso, 
rever o encaminhamento metodológico tornando o conteúdo mais significativo, poderiam favorecer a permanência.

Preocupa ainda o relato das entrevistadas no que concerne à naturalização da evasão nos cursos subsequentes, principalmente quando não há ações efetivas no sentido de compreender esse fenômeno para nele atuar. Nesse sentido, o fato desses cursos não serem considerados prioridade é mais um complicador.

Esperamos, com o decorrer da pesquisa, ouvindo alunos e professores, aprofundar as considerações que ora pudemos indicar e, com base nelas, contribuir para ampliar as discussões sobre os processos de inclusão excludente ainda vigentes na educação profissional.

\section{REFERÊNCIAS}

ANGELUCCI, C.; KALMUS, R.; PATTO, M.H. Educação e Pesquisa, São Paulo, v.30, n.1, p. 51-72, jan./abr. $2004 \mathbf{O}$ estado da arte da pesquisa sobre $o$ fracasso escolar (1991-2002): um estudo introdutório. Disponível em : http://www.scielo.br/pdf/ep/v30n1/a04v30n1.pdf Acesso em 25.05.2019.

CIAVATTA, M. A formação integrada: a escola e o trabalho como lugares de memória e de identidade In: FRIGOTTO, G. et al. (Orgs.). Ensino médio integrado: concepções e contradições. São Paulo: Cortez, 2005. p. 83-105.

FIGUEIREDO, N.; SALES, D. Educação Profissional e evasão escolar em contexto: motivos e reflexões Ensaio: aval. pol. públ. Educ., Rio de Janeiro, v.25, n. 95, p. 356-392, abr./jun. 2017. Disponível em http://www.scielo.br/scielo.php?pid=S0104-

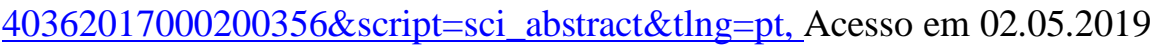

FINI, R; DORE, R; LÜSCHER, A. Insucesso, fracasso, abandono, evasão... um debate multifacetado. In: Formação/Profissionalização de professores e formação profissional e tecnológica fundamentos e reflexões contemporâneas. Daizy Moreira Cunha ET AL. (orgs). Belo Horizonte: Editora PUC Minas, 2013.

JOHANN, C. Evasão escolar no Instituto Federal Sul-rio-grandense: um estudo de caso no campus Passo Fundo. Dissertação de mestrado apresentada ao programa de pósgraduação em educação, da Universidade de Passo Fundo, 2012. Disponível em http://tede.upf.br/jspui/handle/tede/739. Acesso em 02.05.2019.

KUENZER, A. Exclusão includente e inclusão excludente: a nova forma de dualidade estrutural que objetiva as novas relações entre educação e trabalho. In: LOMBARDI, J..; SAVIANI, D.; SANFEICE, J.L. (org) Capitalismo, trabalho e educação. Campinas, SP: Autores Associados, HISTEDBR, 2002.

KUENZER, A. (org.) Ensino Médio: construindo uma proposta para os que vivem do trabalho. São Paulo: Cortez, 2000. 
MACHADO, M. A evasão nos cursos de agropecuária e informática da Escola Agrotécnica Federal de Inconfidentes - MG (2002-2006) Mestrado em Educação UNB 2009. Disponível em http://repositorio.unb.br/bitstream/10482/8676/1/2009_MarciaRodriguesMachado.pdf. Acesso em 10.06.2019

OLIVEIRA, L. S. de. Evasão nos cursos subsequentes do IF-SC Campus Criciúma. Criciúma, SC: Ed. do Autor, 2016. Disponível em:

file:///D:/22.06.2019/PESQUISA/projeto\%20de\%20pesquisa\%20evas\%C3\%A3o/Educa $\% \mathrm{C} 3 \% \mathrm{~A} 7 \% \mathrm{C} 3 \% \mathrm{~A} 30 \% 20$ Profissional $\% 20 \mathrm{e} \% 20 \mathrm{evas} \% \mathrm{C} 3 \% \mathrm{~A} 3 \mathrm{o} \% 20 \mathrm{escolar}$.pdf Acesso em 04.06.2019

SAVIANI, D. Trabalho e educação: fundamentos históricos e ontológicos. Revista Brasileira de Educação v. 12 n. 34 jan./abr. 2007. Disponível em:

http://www.scielo.br/pdf/rbedu/v12n34/a12v1234.pdf Acesso em 23.06.2019.

SETÚBAL. M. a. Equidade e desempenho escolar: é possível alcançar uma educação de qualidade para todos? R. Bras. Est. pedag., Brasília, v. 91, n. 228, p. 345-366, maio/ago. 2010. Disponível em http://rbep.inep.gov.br/index.php/rbep/article/viewFile/577/558, Acesso em 05.05.2019

SUHR, I. Ensino médio: possibilidade de ampliação da inserção laboral da classe que vive do trabalho? Tese (Doutorado em Educação) - Setor de Educação da Universidade Federal do Paraná. Curitiba: 2014. Disponível em:

http://www.ppge.ufpr.br/teses\%20d2014/d2014_Inge\%20Renate\%20Frose\%20Suhr.pdf Acesso em 02.04.20. 